\title{
IDENTIDADES DOCENTES E DISCENTES DA EDUCAÇÃO BÁSICA: tessituras de si
}

\author{
JEOVÂNGELA DE MATOS ROSA RIBEIRO
}

Mestre em Educação e Diversidade. Professora do Instituto Federal da Bahia - Campus Seabra. Pesquisadora do Grupo de Pesquisa Forma(em)Ação - GEFEP UNEB/CNPq. ORCID: 00000001-5475-3647. E-mail: jeovangelarosa@ifba.edu.br

\section{VIVIA SANTOS ANDRADE}

Mestre em Educação e Diversidade. Professora da Rede Municipal de Cansanção/BA. Pesquisadora do Grupo de Pesquisa Forma(em)Ação - GEFEP UNEB/CNPq. ORCID: 00000003-2286-9412. E-mail: andradepedagogia@yahoo.com.br 


\section{IDENTIDADES DOCENTES E DISCENTES DA EDUCAÇÃO BÁSICA: tessituras de si}

Considerando a relevância do debate sobre a construção identitária docente e discente da Educação Básica, problematizaremos, aqui, o processo de construção identitária desses sujeitos, tendo em vista nossa inserção nesse contexto, uma vez que somos professoras com experiências na Educação Básica. Discutiremos esse processo à luz de teóricos como Hall (2014, 2015), Josso (2004, 2006), Bondia (2002), Nóvoa (2009, 2010, 2014), Sales (2009), Rios (2015) dentre outros autores que consubstanciaram o nosso olhar nessa itinerância epistemológica. Nesse contexto, ressaltamos que a reflexão tecida acerca das experiências no contexto perpassa por inúmeros espaços e experiências que, ao longo do percurso de vida e formação, vão constituindo a pessoa que somos. A escrita está ancorada em duas pesquisas de mestrado, nas quais realizamos o movimento de pensar a constituição da identidade docente e discente. Para nós, um entrelaçamento dos fios que nos inquieta refletir sobre como acontece o procedimento em que vamos, cotidianamente, forjando nossa identidade pessoal e profissional -, envolvendo experiências individuais, coletivas e colaborativas, bem como, os estudantes inseridos no contexto da Educação Básica, também, ao longo do percurso, vão tecendo a construção de suas identidades. O percurso metodológico situa-se na perspectiva da pesquisa qualitativa, enveredando pela fenomenologia - hermenêutica. Ainda nessa perspectiva, optamos pelo método (auto)Biográfico e a pesquisa participante, tendo como dispositivos de investigação a entrevista narrativa (JOVCHELOVITCH; BAUER, 2002), o ateliê biográfico com inspiração nas pesquisas desenvolvidas por Delory-Momberger (2012), o grupo focal (GONDIM, 2003) e por fim, a entrevista semiestruturada (TRIVIÑOS, 2009).

Palavras chave: Identidade Docente. Identidade Discente. Educação Básica.

\section{BASIC SCHOOL TEACHER'S AND STUDENT'S IDENTITIES: weaving of oneself}

Considering the importance of the debate on the identity construction of teachers and students from Basic School, we question here about the process of this kind of construction, since we are teachers from Basic Education, immersed in this context. We discuss this process based on some authors such as Hall (2014, 2015), Josso (2004, 2006), Bondia (2002), Nóvoa (2009, 2010, 2014), Sales (2009), Rios (2015), among others who substantiate our view into this epistemological itinerancy. In this context, we emphasize that the critical consideration made about the experiences in the context go through several spaces and experiences which, throughout the life and formation, have been shaping the individual we are. The work is based on two researches from a master degree course in which we did a movement on thinking the constitution of teacher and student identity. We are intrigued by the procedures on how our identity is being formed, day by day, in a personal and professional level, involving individual, collective and collaborative experiences, as well as the procedures of identity construction of students who are immersed in the context of Basic School, and who, through his educational trajectory go weaving the building of their identities. The methodological procedure of this study is based on a qualitative research perspective, supported by hermeneutic phenomenology. Yet in this perspective, we chose the autobiographical method and participant research, having used as research devices the narrative interview (JOVCHELOVITCH; BAUER, 2002), the biographic atelier inspired on researches developed by Delory-Momberger (2012), the focus group (GONDIM, 2003) and, at last, the semi-structured interview (TRIVIÑOS, 2009).

Keywords: Teacher Identity. Student Identity. Basic School. 


\section{IDENTIDADES DOCENTES Y DISCENTES DE LA ENSEÑANZA BÁSICA: tesituras de si}

En vista de la significación del debate sobre la construcción de la identidad docente y discente de la Enseñanza Básica, discutiremos, aquí, el proceso de construcción de la identidad de esos sujetos, teniendo en cuenta nuestra inserción en ese contexto, una vez que somos maestras con experiencias en la Enseñanza Básica. Debatiremos ese proceso desde el punto de vista de teóricos como Hall (2014, 2015), Josso (2004, 2006), Bondia (2002), Nóvoa (2009, 2010, 2014), Sales (2009), Rios (2015) entre otros autores que corroboraron con nuestra mirada en esa itenerancia epistemológica. En ese contexto, subrayamos que la reflexión tejida en cuanto a las experiencias en el contexto atraviesa inúmeros espacios y experiencias que, a lo largo de la trayectoria de vida y formación, van construyendo la persona que somos. La escrita está anclada a dos investigaciones de maestría, en las cuales realizamos el movimiento de pensar en la constitución de la identidad docente y discente. Para nosotros, un enredo de dos hilos que nos preocupa reflexionar sobre como ocurre el procedimiento en que vamos, diariamente, forjando nuestra identidad - personal y profesional -, involucrando experiencias individuales, colectivas y colaborativas, así como, los estudiantes insertados en el contexto de la Enseñanza Básica, también, en el trayecto, van tejiendo la construcción de sus identidades. El recorrido metodológico está basado en la perspectiva de la investigación cualitativa, siguiendo por el camino de la fenomenología - hermenéutica. Siguiendo en ese punto, elegimos el método (auto) Biográfico la investigación participante, teniendo como dispositivo de estudio la entrevista narrativa (JOVCHELOVITCH; BAUER, 2002), el taller biográfico inspirados en las investigaciones desarrolladas por Delory-Momberger (2012), el grupo de enfoque (GONDIM, 2003) y por último, la entrevista semiestructurada (TRIVIÑOS, 2009)

Palabras clave: Identidad Docente. Identidad Discente. Enseñanza Básica. 


\section{IDENTIDADES DOCENTES E DISCENTES DA EDUCAÇÃO BÁSICA: tessituras de si}

\section{Introdução}

A Educação Básica é um espaço de efervescência em que pulsa a diversidade humana; é um ambiente destinado a receber todos àqueles que a ele têm direito garantido por Lei. Sendo assim, pensar nessa diversidade de pessoas, e de subjetividades, que permeiam à constituição do ser de cada individuo, nos impele a caminhar pelo estudo e compreensão do processo de construção identitária de professores e estudantes que compõem esse universo tão amplo que é a Educação Básica.

Enveredar por essas discussões nos possibilita pensar de maneira mais ampla, e caleidoscópica, acerca da formação docente e os aspectos inerentes ao processo de construção de sua identidade, bem como, nos elementos presentes na trajetória formativa dos estudantes da Educação Básica que se entrelaçam na perspectiva da sua constituição identitária.

Diante disso, pensar a formação docente, no que consiste a constituição de sua identidade, é uma perspectiva que vem, ao longo dos últimos anos, ganhando espaço e se consolidando por meio de estudos científicos desenvolvidos nas academias. Sendo mais especificas, apenas na década de 80 do século passado é que se registra o início desses estudos na perspectiva da formação docente, em que o olhar se volta à trajetória de vida, o que desemboca no cerne da questão identitária. Para além de discutir a identidade docente, nos propomos, também, realizar um sobrevoo sobre a construção da identidade discente. Para tanto, traçamos como objeto desse texto o processo de construção identitária dos professores e estudantes da Educação Básica.

Caminhar por essa perspectiva nos permite aprofundar reflexões sobre questões que permeiam a nossa própria formação, ampliando o olhar acerca dos elementos que constituem, também, a nós mesmos enquanto personagens que compõem o cenário educacional. Assim, partiremos da premissa de delinearmos algumas reflexões acerca do processo de construção identitária docente e discente dentro das experiências vivenciadas nos espaços escolares.

Nesse contexto, o caminho foi/é pensado e planejado partindo de alguns pressupostos metodológicos, e escolhido por aproximações que, julgamos pertinentes. Entendemos o percurso metodológico como um desenho, um mapa que orienta a nossa trajetória nas encruzilhadas

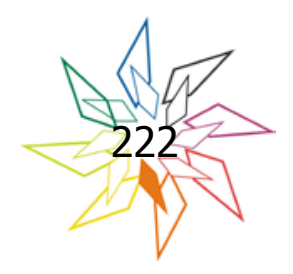


do conhecimento. Na definição apresentada por Houaiss (2004, p.494), metodologia "é um conjunto de métodos, princípios e regras empregados por uma atividade ou disciplina". Diante disso, entendemos que traçar o percurso metodológico nos permite dispor de instrumentos para caminhar pelas veredas do saber, guiado por um objeto de pesquisa ou investigação que nos inquieta e fomenta no processo da pesquisa, possibilitando descortinar a realidade vivenciada por todos, sujeitos da trama e da história cotidiana.

\section{Entrelaces Metodológicos}

Este artigo traz um recorte de duas pesquisas ${ }^{1}$ realizadas em Programa de Pós Graduação stricto sensu, vinculadas ao Grupo de Pesquisa Forma (em)Ação - GEFEP UNEB/CNPq .

Aqui, discutiremos identidade docente e discente na Educação Básica. Por se tratar de pesquisas direcionadas ao campo educacional, compreendemos a relevância em caminhar pelas veredas da pesquisa qualitativa por acreditar que seja a mais apropriada para o que estamos nos propondo a fazer.

Ao enveredarmos pela pesquisa com pressupostos na construção identitária, compreendemos que a escolha pela investigação de cunho qualitativo permite aos investigadores aproximaremse da subjetividade humana no intuito de compreendê-la e estabelecer diálogos. Para Creswell (2010, p. 26) "A pesquisa qualitativa é um meio para explorar e para entender o significado que os indivíduos ou os grupos atribuem a um problema social ou humano. [...]". Nesta compreensão, escolhemos o caminho voltado para a pesquisa com o método (auto)biográfico (NÓVOA, 2010) e a pesquisa participante (ESTEBAN, 2010).

Partindo desse princípio, as escolhas foram/são de caminhar pela fenomenologia - hermenêutica (MACEDO, 2000; CRESWELL, 2010). Os dispositivos para a construção das informações, no decorrer das pesquisas, se deram em torno da entrevista narrativa (JOVCHELOVITCH; BAUER, 2002), do ateliê biográfico com inspiração nas pesquisas

\footnotetext{
${ }^{1}$ URIBEIRO, Jeovângela de M. R. SINGULARIDADES E DIVERSIDADES CULTURAIS NA EDUCAÇÃOPROFISSIONAL: um estudo da identidade discente no IFBA Campus Seabra. (TCFC) Programa de Pós-graduação Educação e Diversidade. Universidade do Estado da Bahia. Jacobina/BA, 2016. ANDRADE, Vívia Santos. O EXERCÍCIO DA DOCÊNCIA NA FORMAÇÃO DE PROFESSORES: identidades docentes no município de Cansanção - B. (TCFC) Programa de Pós-graduação Educação e Diversidade. Universidade do Estado da Bahia. Jacobina/BA, 2016. ${ }^{2}$ Para saber mais, ver em http://dgp.cnpq.br/dgp/espelhogrupo/2292907583398667.
} 
desenvolvidas por Delory-Momberger (2012), do grupo focal (GONDIM, 2003) e, por fim, da entrevista semiestruturada (TRIVIÑOS, 2009).

Por se tratar de um Mestrado Profissional, ao longo do percurso investigativo foram se desenhando duas propostas de intervenção no ambiente/lócus das pesquisas. Sendo assim, eis que ganha corpo um Memorial Formação (PASSEGGI, 2010, SALES, 2009), o qual foi construído a muitas mãos com o intuito de registrar a trajetória formativa docente no município de Cansanção/ BA e de compreender o processo de construção identitária dos sujeitos envolvidos.

Outro formato relacionado à pesquisa sobre a identidade do estudante no IFBA Campus Seabra, foi o Documento Referencial, organizado com proposições compostas de um conjunto de ações para o processo educativo do Instituto, envolvendo servidores (docentes e técnicos) e, educandos. Tais proposições devem ser implantadas no IFBA Campus Seabra, com o objetivo de fortalecer a valorização das identidades existentes nas diversidades socioculturais dos estudantes, contribuindo para a qualificação das práticas pedagógicas nesse Instituto.

Os personagens que ilustram essa história são professoras e estudantes da rede pública baiana de ensino; sendo cinco professoras pertencentes à rede no município de Cansanção que desenvolvem suas atividades docentes nos anos iniciais do Ensino Fundamental na Escola Educandário Senhora Santana. Os estudantes participantes da pesquisa, são dezesseis educandos dos Cursos Técnicos em Meio Ambiente e Informática, na modalidade integrado, do IFBA Campus Seabra.

As pesquisas em tela dialogam sobre identidade docente e discente e, ao longo desse texto, vamos entrelaçar alguns dos fios construídos ao longo do percurso da investigação que se enredam, constituindo, assim, uma rica trama de saberes.

\section{IDENTIDADE DOCENTE: tessituras de si}

As discussões sobre identidade docente nas três últimas décadas se encontram no centro dos debates e investigações acerca do professor e sua formação, permeando os conceitos e suas especificidades, na qual considera a trajetória de vida e formação desse profissional, bem como, os aspectos intrínsecos às suas experiências. Desse modo, voltamos "o olhar preferencialmente

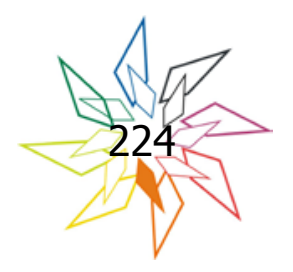


para a ligação entre as dimensões pessoais e profissionais na produção identitária dos professores" (NÓVOA, 2009, p. 29).

Discutir o cerne da questão sobre identidade dos professores que atuam na Educação Básica, nos impele a pensar nos entrelaçamentos existentes entre o processo de construção dessa identidade e a formação profissional e pessoal docente (NÓVOA, 2013). Muitos teóricos se debruçam nessa perspectiva para compreender como se constrói a identidade docente e os entrelaces existentes com a formação. Para tanto, consideramos que os fios se entrecruzam ao longo do caminho, ou seja, a formação e a construção identitária vão sendo tecidas, concomitantemente, no percurso de vida. Para Nóvoa (2013, p. 15),

O professor é a pessoa; e uma parte importante da pessoa é o professor. Estamos no cerne do processo identitário da profissão docente que, mesmo nos tempos áureos da racionalização e da uniformização, cada um continuou a produzir no mais íntimo da sua maneira de ser professor. (grifos do autor).

Ancoramo-nos, também, em Hall (2014, p.109) para delinearmos o entendimento necessário na construção de nosso conceito para identidade. As identidades "[...] têm a ver, entretanto, com a questão da utilização dos recursos da história, da linguagem e da cultura para a produção não daquilo que nós somos, mas daquilo no qual nos tornamos [...]". É pensando nessa trajetória, nesse percurso, no entrelace das experiências vivenciadas pelos sujeitos que se evidenciam as imbricações na construção de sua subjetividade e, consequentemente, na constituição do que nos tornamos, no processo de devir. Percebemos essa questão nas palavras da professora Flor de Cactos $^{3}$,

A minha tia ela era professora, professora leiga; foi ela que me alfabetizou, e eu me inspirava muito no que ela fazia, nos desenhinhos que ela cortava pra arrumar minhas provas, nas atividades. Como a dificuldade naquela época era grande, ela cortava, ela não podia vê um desenhinho, e aquilo foi me inspirando, que eu achava bonito, a arte que ela, a qual ela usava pra fazer os trabalhos dela como professora. (ENTREVISTA NARRATIVA, 2017).

Partindo dessa perspectiva, nos reportamos à discussão acerca da relevância de pensar e discutir os preceitos da construção identitária docente - vimos constituindo nossas identidades docentes e acompanhando o processo da constituição da identidade dos nossos discentes; vimos

\footnotetext{
${ }^{3}$ As professoras colaboradoras foram identificadas ao longo do texto com nomes de flores, escolhidos por elas, no decorrer da aplicação dos ateliês biográficos, atendendo aos princípios éticos da pesquisa para manter seus nomes sob sigilo.
} 
acompanhando os deslocamentos identitários (HALL, 2015) que nossos estudantes passam trazer para a comunidade educativa suas particularidades sociais, culturais e econômicas.

Para adentrarmos com maior propriedade no estudo da identidade docente e discente, partimos das nossas próprias experiências tecidas nos anos vivenciados na docência da Educação Básica. É por meio da História de Vida e das experiências vividas que buscamos refletir os significados presentes na trajetória formativa e que, ao rememorar, rendem a construção do caleidoscópio de quem vamos nos tornando, ao longo do caminho. Para Josso (2006, p. 27), “(...) a educação e formação são processos de transformação, múltiplos projetos habitam, tecem, percorrem, dinamizam e programam os relatos das histórias de vida e também nos informam sobre os desejos de ser e de vir-a-ser de seus autores."

Ao puxar esses fios da memória, evocamos algumas experiências que, ao serem trazidas para o campo da reflexão, são percebidas como elementos intrínsecos à nossa constituição identitária. Iniciamos pelo sentimento de pertencimento do lugar ao qual estamos inseridas, perpassando pelas vivencias no contexto social, com a cultura singular da comunidade e dos grupos ao qual pertencemos, os fatores religiosos, políticos entre outros.

Outra professora colaboradora traz algumas pistas desse sentimento de pertencimento,

Prefiro falar da escola de onde eu comecei, porque foi onde tudo começou, onde eu dei os meus primeiros passos na minha vida. Monte Santo foi importante, mas eu prefiro falar da escola onde eu comecei, eu me sinto melhor. (Rosa, ENTREVISTA NARRATIVA, 2017).

É no olhar ontológico da singularidade, ou melhor, das particularidades do lugar e das pessoas com quem convivemos que os fios vão emergindo e sendo tecidos no tear da experiência. Para Rios (2015, p. 37),

A formação do(a) professor(a) passa pelo lugar de produção da pessoa, pelos diferentes movimentos constitutivos de suas identidades. Dizer quem é, quais foram seus processos de formação e suas experiências de formação são ações presentes nas diversas histórias de vida dos(as) docentes.

Ser professora, principalmente na atual conjuntura, na qual sofremos retrocessos brutais, inclusive, ameaças veementes na liberdade de expressão, de discussões nos espaços escolares e de representatividade da diversidade que constituem a escola, nos provoca pensar na pertinência de desenvolver estudos acerca da constituição identitária, que por sua vez, encontra-se atrelada ao contexto histórico, social e político.

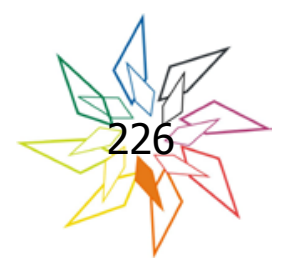


Essas questões também levantam discussões para a diversidade cultural existente nos espaços escolares para conhecer o educando, suas histórias de vida, sua forma de pensar e agir, suas identidades; e entender o processo do deslocamento dessas identidades na unidade escolar, constitui um desafio para a educação na atualidade, entendendo a escola como um lugar de pertencimento para esse público. Para Gatti (2015, p. 26) "[...] sem a Educação Básica, os indivíduos historicamente existentes são seres culturalmente incompletos [...]”.

Sendo assim, a escola pública é o nosso ponto de partida e chegada de onde trazemos nossas perspectivas de construção e entrelaçamento de identidades, atravessando, assim, o contexto educacional. Um lugar do qual nossas vozes polifônicas são emitidas; é nessa mistura singular que se entrelaça a nossa condição humana constituída de subjetividade, linguagem e símbolos; que emergem fios responsáveis pela costura dos pontos que vão tecer o nosso ser, registrando, aí, nossas experiências.

A Educação Básica sempre foi um campo de lutas, por conta disso, aprendemos desde cedo a ser fortes e perseverantes naquilo que desejamos; a não esmorecer com as dificuldades e desafios a serem enfrentados ao longo da trajetória. Mas, quando adentramos no campo educacional como professoras, não tínhamos dimensão das dificuldades a serem enfrentadas ao longo da caminhada. Inúmeros confrontos e enfrentamentos foram necessários para continuarmos no percurso que tínhamos escolhido seguir. Contudo, ao rememorarmos as experiências vivenciadas em nossa trajetória docente, percebemos o quanto as dificuldades foram importantes para o processo de constituição e formação das professoras em que nos tornamos. Sales $(2009$, p. 48) nos inspira nessa reflexão,

Somos as histórias das nossas invenções, nossos corpos não terminam na pele: sempre animamos as máquinas, dando-lhes gestos e ações. Cabe-nos, assim, formular nossas questões para além do que somos, mais do que somos capazes de fazer, inclusive com o que somos.

Assim, entendemos que a identidade é processo, construção; compreendemos que, esta vai se constituindo ao longo do exercício da docência, no entrelaçar das experiências vividas, no desenvolvimento das atividades dentro e fora do espaço escolar. Tais experiências são particularmente singulares para quem as vive, produzindo sentidos específicos para cada um, ou seja, cada experiência que toca o sujeito que a vive é sentida de maneira única, particular, não sendo possível ser compreendida da mesma maneira por todos os que a experimentaram. Larosa $(2002$, p. 27) diz que,

[...] Se a experiência não é o que acontece, mas o que nos acontece, duas pessoas, ainda que enfrentem o mesmo acontecimento, não fazem a mesma experiência. $\mathrm{O}$ acontecimento é comum, mas a experiência é para cada qual sua, singular e de 
alguma maneira impossível de ser repetida. O saber da experiência é um saber que não pode separar-se do indivíduo concreto em quem encarna.

Compreendemos, então, que a experiência está diretamente vinculada ao processo de construção identitário docente e discente; pois são as vivências ocorridas nos diversos espaços e com os nossos pares, que podem se converter em experiências. Desse modo, percebemos que as vivências, sentidas e refletidas, podem se transformar em experiências, que por sua vez, vão se entretecendo no tear da vida, enredando os fios no processo cotidiano de construção identitária (JOSSO, 2004).

Sendo assim, percebemos que problematizar a construção da identidade docente na perspectiva da sua trajetória de vida, trazendo para o centro da ciranda as suas experiências, principalmente, junto aos discentes, é um dos caminhos de reconhecimento e visibilidade da importância de considerar a subjetividade humana, imbricada à pessoa do professor, em todo o seu processo formativo.

Trazer essa discussão para dentro das escolas na Educação Básica é o começo de um grande movimento, revolucionário inclusive, de investigação acerca da formação docente pela perspectiva de construção identitária. Ouvir o que os professores da Educação Básica têm a contar de si, de suas experiências, compreender os significados que eles atribuem a toda a itinerância formativa, pode ser o começo para uma grande viragem (Nóvoa, 2009) na educação do nosso país. Percebemos essa evidência na expressão da professora Margarida, participante da pesquisa, ao relatar a relevância de escrever as suas memorias.

No meu caso, a sensação de escrever eu imaginei o cenário direitinho. Se eu fosse construir uma maquete, acho que eu construiria igualzinho. Aí o engraçado, a sensação não é só do cenário, é capaz que a gente ouça até o barulho de tão que a gente ficou marcado. (ATELIÊ BIOGRÁFICO, 2017)

Mediante a esse movimento de visibilidade da pessoa do professor, está a organização da Educação Básica. Nós que estamos inseridos nessa itinerância, nos deparamos com um formato de educação que ainda não abarca as premissas sociais, culturais, econômicas e políticas concernentes ao nosso lugar de reconhecimento.

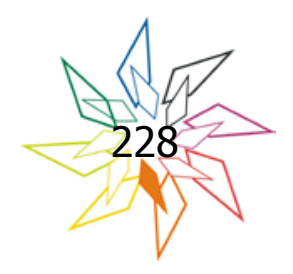




\section{IDENTIDADE DISCENTES: fios que se intrelaçam}

Sendo professoras da Educação Básica, as vivências no cotidiano escolar, possibilitam que as nossas experiências sejam construídas na relação direta com os discentes, no contato com os universos culturais heterogênicos existentes no chão da escola ${ }^{4}$. Essa realidade contribui para o movimento de construção da identidade tanto docente, quanto discente; esses fios que se entrelaçam nessas vivências nos têm revelado momentos ricos de trocas de saberes, pois a educação é via de mão dupla, consubstanciando desse modo, essas vivências em experiências.

Para ratificar essa discussão, apresentamos, aqui, resultados parciais da pesquisa desenvolvida no IFBA Campus Seabra, quando buscamos investigar a identidade do estudante da Educação Profissional, partindo do conhecimento da diversidade sociocultural dos estudantes participantes da pesquisa. O movimento de incertezas e de lutas, ao mesmo tempo, requer o fomento à liberdade de ideias e a construção autônoma de um ser histórico que traz imbuído em sua subjetividade os aspectos socioeconômicos e socioculturais. A democratização do acesso à educação pública no Brasil trouxe para dentro dos espaços escolares uma população de crianças e jovens que tinha, até então, esse direito negado. A ampliação do número de estudantes emergiu na escola uma realidade composta por diferentes identidades, variados saberes e forma de enxergar o mundo, o que fez emergir uma diversidade cultural nos entremuros da escola. Essa realidade é percebida, também, nas escolas do Semiárido baiano, bem como na Educação Profissional, desenvolvida pelos Institutos Federais.

Os diversos contextos socioculturais e econômicos existentes nas escolas nordestinas englobam ricas experiências de vida de estudantes oriundos do campo e da cidade, o que reporta para várias visões pessoais do mundo em que vivemos. Dentro da diversidade cultural, a singularidade de cada ser é valorizada. Nesse contexto, Laraia (2001, p.36) nos diz que,

(...) o modo de ver o mundo, as apreciações de ordem moral e valorativa, os diferentes comportamentos sociais e mesmo as posturas corporais são, assim, produtos de uma herança cultural, ou seja, o resultado da operação de uma determinada cultura.

A escola reconhecida como palco de interação cultural; através da troca de experiências, tem o papel de promotora de valorização do outro, e é reconhecida por McLaren (2000) como

\footnotetext{
${ }^{4}$ Utilizamos esse termo para expressar nossa relação direta com a realidade da escola e nossa ligação com o cotidiano escolar estabelecida pela docência.
} 
uma tecnologia que impulsiona a mudança na sociedade, através da pluralidade cultural. Nessa perspectiva, as escolas do Semiárido baiano são um dos fios importantes no processo de construção da identidade do estudante.

Nesse sentido, através dos resultados da pesquisa, foi possível verificar que dentre os estudantes, interlocutores do estudo, a diversidade representada é constituída por jovens, com a faixa etária compreendida entre 16 a 22 anos - uma população composta por $80 \%$ de negros, $83 \%$ se identificam com o sexo feminino, $86 \%$ pertencem a outros municípios circunvizinhos, como Palmeiras, Piatã, Iraquara, Lençóis, Boninal, Bonito, dentre outros do Território de Identidade da Chapada Diamantina e estudantes do campo.

O estudante Poço Encantado ${ }^{5}$, em seu relato abaixo, é um exemplo dessa diversidade.

(...) o modo de ver o mundo, as apreciações de ordem moral e valorativa, os diferentes comportamentos sociais e mesmo as posturas corporais são, assim, produtos de uma herança cultural, ou seja, o resultado da operação de uma determinada cultura.

Essa diversidade existente nos traz, também, outras nuances como a importância do processo educativo para o fortalecimento da identidade de cada estudante. A exemplo disso, o relato do estudante Rio Preto reconhece a influência da escola na constituição de sua autoafirmação, tanto na sua identificação enquanto negro, quanto em sua orientação sexual.

Antigamente não me assumia enquanto negro. A partir daqui (IFBA) eu me conscientizei que eu sou negro, resgatando minha identidade. Também tinha receio de dizer que era homossexual. Então, foi muito importante a construção, a construção política para poder me ajudar na minha vida. (Rio Preto, Relato Oral, 2017).

Esse relato fortalece a concepção de que a construção da identidade é um processo contínuo de construção. Nessa interpretação, Moreira e Candau (2014, p.28) enfatizam que na atualidade "os processos de hibridização cultural são intensos e mobilizadores da construção de identidades abertas."

Ainda carecemos de movimento de resistência que se fortaleça na caminhada com a educação como processo voltado para a convivência com o Semiárido, para a construção de um

\footnotetext{
${ }^{5}$ Com o objetivo do anonimato dos participantes, nesta pesquisa, para a identificação foi escolhido um nome de um atrativo turístico da Chapada Diamantina.
}

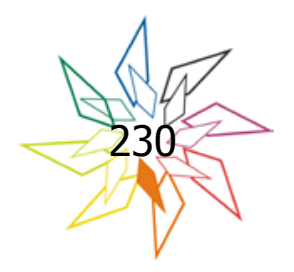


ser humano autônomo e capaz de conviver com as especificidades típicas regionais, e no contexto em que vive. O relato da estudante Cachoeira da Fumaça, a seguir, fortalece o papel da educação quando evidencia a importância da escola na formação da autonomia do estudante, além de demonstrar a importância do processo educativo para o fortalecimento da sua identidade.

Eu acho que o IFBA, além de nos formar para o mercado de trabalho, ele nos faz sujeitos críticos, a gente sai daqui com uma autonomia e um amadurecimento diferente do que a gente teria estudando em uma escola municipal ou estadual. Acho que o ensino aqui nos forma mais preparados para a vida; não só para o mercado de trabalho, você sai muito mais madura. Eu sou muito diferente de quando eu entrei aqui, eu entrei insegura, sem opinião, hoje eu sei como formar minha opinião, eu sei o que fazer para procurar e decidir, que lado eu vou ficar de um determinado assunto, como estudar, o que estudar e é isso. (Cachoeira da Fumaça, Relato Oral, 2017).

Esse relato traz um ponto crucial para a educação: a relevância em desenvolver atividades educativas que não visem a transmissão de conteúdo, mas que busquem a valorização do estudante enquanto sujeito de sua própria história, através do fortalecimento dos elementos constituintes de suas identidades.

A Escola tem como desafio o de conhecer o educando e, para isso, deve promover "processo de ampliação dos horizontes culturais dos estudantes." (MOREIRA e CANDAU, 2014, p. 14), O conhecimento do estudante, se mostrou dentro da pesquisa desenvolvida como um movimento importante para o fortalecimento da identidade do educando. Essa conclusão, foi possível através da escuta de outro participante da pesquisa.

Antigamente não me assumia enquanto negro, a partir daqui (IFBA) que eu me conscientizei que eu sou negro, resgatando minha identidade, também tinha meio que receio de dizer que eu era homossexual, então tipo assim foi muito importante a construção, a construção política para poder me ajudar na minha vida. (Rio Preto, Relato Oral, 2017).

É na convivência com o outro na escola, que os estudantes vivenciam situações em que se tornam significativas para ele enquanto sujeito aprendente. Nessa ciranda de construção de saberes, dentro dos muros da escola que tanto nós, professores, quanto os estudantes vão construindo o seus símbolos, o seu imaginário, ampliando o olhar sobre si mesmo enquanto sujeito que aprende, individual e coletivamente. 
A educação, tecida na relação entre professor e estudante, dentro e fora dos espaços escolares, colabora, significativamente, para o processo de subjetivação, além de ampliar as redes das vivencias que serão, posteriormente, refletidas como experiências presentes no processo de construção identitário de ambos.

Esse movimento de interação é importante para o fortalecimento dessas identidades docente e discente -, que estão sempre em construção através das experiências que vão sendo adquiridas. Assim, concordamos com Souza Santos (2008, p.135) para quem "as identidades culturais não são rígidas nem, muito menos imutáveis. São resultados sempre transitórios e fugazes de processos de identificação. Identidades são, pois, identificações em curso". Essa dinâmica é observável no relato da estudante Cachoeira do Mosquito, quando reconhece a importância de um dos eventos desenvolvidos na escola - Semana Preta -, para a autoafirmação e empoderamento da negritude no espaço escolar.

Aqui no IFBA tem muito disso, das pessoas se empoderarem e eu acho que é muito importante essas coisas, porque as pessoas se autoafirmam e também tem Semana Preta que ajuda muitas pessoas mesmo como eu já vi muita Semana Preta as pessoas se emocionando com que é passado lá, com o que é discutido; e também muda muito as pessoas. (Cachoeira do Mosquito, Relato Oral, 2017).

Dessa forma, entendemos que estamos sempre em construção e que as nossas experiências vão influenciar nas nossas visões de mundo. Quando nos relacionamos com os nossos estudantes, conhecendo a existência social, cultural e política de cada um/a, vamos nesse processo nos constituindo; ao compreender as especificidades dos estudantes que convivem conosco, cotidianamente, nos espaços escolares e conhecermos sua comunidade, passamos a conhecer os signos que não faziam parte da nossa existência. Conhecendo suas realidades, vamos construindo nossas itinerâncias; bem como, os estudantes simultaneamente, tecem os fios que os constituem como sujeitos imbuídos de subjetividades.

Nesse entrelaçar, surgem caminhos para a construção de pontes entre os educadores e os estudantes, para isso é válido ouvir os jovens. No estudo em questão as lacunas existentes, como a demonstrada pelo o estudante Morro Branco em seu relato, constituem em um direcionamento para a busca de soluções.

Eu acho que a prática docente contribui bastante, mas, ainda é muito limitado algumas matérias (...), principalmente as matérias de Humanidades que discutem mais a questão do respeito das diversidades cultural e religiosa, sexual. As matérias técnicas não fazem esse tipo de discussão né?! Pode citar o caso da Lei 10.639: pouquíssimos professores, a não ser os de História,

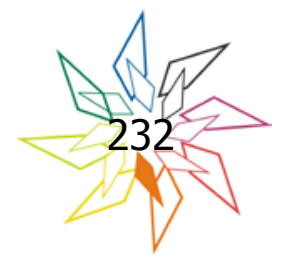


Geografia e Filosofia trazem essa discussão para dentro da sala de aula. Eu entendo que, às vezes, os professores não tiveram uma formação para aquilo, mas se é obrigatório, é uma lei né?! Eu acho que o professor deve correr atrás e tentar inserir dentro das áreas técnicas, tem como inserir isso dentro da Informática, dentro da Matemática, na Física e tudo mais. (Morro Branco, Relato Oral, 2017).

O conhecimento dessa realidade, apontada pelo estudante, é um diagnóstico importante para o planejamento de ações que visem a mitigação do problema apontado. O profissional de educação tem a oportunidade de entender o que realmente está acontecendo e a partir daí, buscar caminhos para a transformação. É claro que é um trabalho conjunto, que envolve a direção, coordenadores, funcionários, pais, estudantes e docentes.

Esse processo de troca de experiências enriquece a construção da identidade social da escola, além da construção da identidade pessoal do professor e do estudante. A experiência pessoal é acrescida substancialmente pela contribuição do outro. Nesse processo de construção, Binja (2015, p.53-54) nos diz que,

[...] identidade refere-se ao conjunto de caracteres próprios e exclusivos com os quais o agente pode diferenciar de outros agentes, por outro ela também consiste na soma nunca concluída de um aglomerado de signos, referências e influências que definem o entendimento relacional do agente, percebida geralmente por contraste, vale dizer, pela diferença. A identidade está sempre relacionada com a noção do outro e dos compromissos e identificação do agente humano.

A relação com o outro é o elemento constitutivo das experiências pessoais; nesse movimento de interação se dá o contato entre o professor e o estudante através do processo educativo existente no ambiente escolar. Esse diálogo, realizado através de uma troca de respeito mútuo, valorizando o outro como um complemento importante para a construção do saber, nutre uma riqueza indiscutível no processo pessoal de construção do ser. Dessa forma, conhecer quem é o estudante da Educação Básica, suas formas de ser e pensar o mundo, ou seja, sua identidade é um passo importante para a interação entre os docentes e discentes.

É nesse sentido de valorização da experiência, enquanto fios que se enredam na construção dos sujeitos, que apontamos a relevância dessas experiências tecidas no espaço escolar da Educação Básica, no qual se considere a realidade em que estamos todos inseridos, que possamos, enquanto professoras, contribuir para o desenvolvimento, colaborativamente, redes que teçam os fios que emergem, cotidianamente, na relação entre sujeitos aprendentes. 


\section{CONCLUSÕES - Tessituras da Identidade}

Ao escrever esse texto, para além de processo de retomada de algumas ideias, laçamos mão de refletir sobre nossas experiências vivenciadas em nossa trajetória docente vivenciada no cenário da Educação Básica, ao qual estamos inseridas - seja como docentes e/ou como pesquisadoras, provocando um movimento de reorganização nas ideias,

Pensar sobre a constituição identitária na perspectiva da experiência toma uma dimensão ampla e impossível de comunicar por completo, uma vez que a experiência é única e intransferível. Contudo, compreendemos que a partir das reflexões acerca das vivências no espaço escolar e fora dele, vamos, enquanto sujeitos aprendentes, construindo a nossa identidade.

A identidade docente vai sendo construída através da interligação da construção identitária do discente, ou seja, a identidade pessoal do professor é influenciada diretamente pela identidade pessoal do estudante ao qual o docente tem relação. No cotidiano escolar as relações tecidas entre os professores e estudantes proporcionam um processo dinâmico, movimento que dentro de suas peculiaridades vai delineando a identidade social da escola. Partindo do pressuposto de que a identidade não é algo pronto, acabado e/ou cristalizado, que se encontra em permanente processo de construção, entendemos que a nossa itinerância na Educação Básica, vai desenhando esse processo gradativamente e de maneira ininterrupta. Desse modo, assim como a nossa identidade vai se tecendo nesse movimento, a discente, também inserida nesses percursos, vai sendo forjada no calor da convivência consigo mesmo e com o outro.

Provocar essa discussão fomenta, em nós, o desejo de ampliar o olhar caleidoscópico para o contexto em que estamos inseridas. Ser sertanejas, reconhecer as possibilidades de convivência nesse espaço de resistência e luta reforça o empenho em continuar na caminhada para o fortalecimento da educação, nos impele a pensar sobre as especificidades desses lugares que diz muito de nós mesmos.

\section{REFERÊNCIAS}

BINJA, Elias. Multiculturalismo: a identidade do sujeito nas tensões sociais contemporâneas em Charles Taylor. São Paulo: LiberArs, 2015.

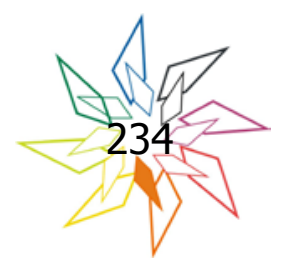


BONDÍA, Jorge Larrosa. Notas sobre a experiência e o saber de experiência. Revista Brasileira de Educação, Jan/Fev/Mar/Abr 2002 No 19. Disponível em: http://www.scielo.br/pdf/rbedu/n19/ n19a02.pdf Acessado em 10/02/2016

CRESWELL, Jonh W. Projeto de pesquisa: métodos qualitativos, quantitativos e mistos. Tradução Magda Lopes; consultoria, supervisão e revisão técnica desta edição Dirceu da Silva. $3^{\mathrm{a}}$ ed. Porto Alegre: Artmed, 2010.

DELORY - MOMBERGER, Christine. A pesquisa biográfica: projeto epistemológico e perspectivas metodológicas. In: ABRAHÃO, Maria Helena Barreto; PASSEGGI, Maria da Conceição (Orgs.). Dimensões epistemológicas e metodológicas da pesquisa (auto)biográfica: Tomo I. Natal: EDUFRN; Porto Alegre: EDIPUCRS; Salvador: EDUNEB, 2012.

ESTEBAN, Maria Paz Sandin. Pesquisa qualitativa em educação: fundamentos e tradições. Porto Alegre: 2010.

GATTI, Bernadete Angelina. Políticas educacionais e educação básica: desafios para as práticas e formação docente. In: RIOS, Jane Adriana Pacheco (org.). Políticas, práticas e formação na educação básica. Salvador: EDUFBA, 2015

GONDIM, Maria Sônia Guedes. Grupos focais como técnicas de investigação qualitativa: desafios metodológicos. Revista Paidéia. UFBA, 2003, 12(24), 149-161.

HALL, Stuart. Quem precisa da identidade? In.: SILVA, Tomaz Tadeu da (Org.). Identidade e diferença: a perspectiva dos estudos culturais.15ª ed. Petrópolis: RJ, Vozes, 2014.

Stuart. A identidade cultural na pós-modernidade. Rio de Janeiro: DP \& A, 2015.

HOUAISS, Antonio. (org.) Minidicionário Houaiss da língua portuguesa. $2^{\mathrm{a}}$ ed. Rio de Janeiro: Objetiva, 2004.

JOVCHELIVITCH, Sandra; BAUER, Martin W. Entrevista Narrativa. In.: BAUER, Martin W; GASKELL, George. Pesquisa qualitativa com texto: imagem e som: um manual prático; tradução de Pedrinho A. Guareschi. Petrópolis: RJ, Vozes, 2002.

JOSSO, Marie-Christine. Experiências de vida e formação. Tradução José Cláudino e Júlia Ferreira. São Paulo: Cortez, 2004. 
. Os relatos de histórias de vida como desenvolvimento dos desafios existentes da formação e do conhecimento: destinos sócio-culturais e projetos de vida programados na invenção de si. In.: SOUZA, Elizeu Clementino, ABRAHÂO, Maria Helena Menna Barreto (Orgs.) Tempos, narrativas e ficções: a invenção de si. Porto Alegre: EDIPUCRS; EDUNEB, 2006.

LARAIA, R. B. Cultura: um conceito antropológico. Rio de Janeiro: Zahar, 2001.

MACEDO, Roberto Sidnei. A Etnopesquisa crítica e multirreferencial nas ciências humanas e na educação. Salvador: EDUFBA, 2000.

MCLAREN, Peter. Multiculturalismo Crítico. São Paulo: Cortez, 2000.

NÓVOA, António. Professores: imagens do futuro presente. Educa: Lisboa, 2009.

António; FINGER, Matthias (Orgs). O método (auto)biográfico e a formação. Natal, RN: EDUFRN; São Paulo: Paulus, 2010. Profissão professor. Porto: Porto Editora, 2014.

PASSEGGI, Maria da Conceição. Memoriais autobiográficos: escritas de si como arte de (re) conhecimento. In: CORDEIRO, Verbena Maria Rocha; SOUZA, Elizeu Clementino de (Orgs.). Memoriais, literatura e práticas culturais de leitura. Salvador: EDUFBA, 2010.

RIOS, Jane Adriana Vasconcelos Pacheco. Profissão docente na roça. Salvador: EDUFBA, 2015.

SALES, Márcea Andrade. Arquitetura do desejo de aprender: autoria docente em debate. 2009. 154 f. Tese (doutorado). Programa de Pós-graduação em Educação. Universidade Federal da Bahia, Faculdade de Educação. Salvador/BA, 2009.

SANTOS, Boaventura de Souza. Pela mão de Alice: o social e o político na pós-modernidade. São Paulo: Cortez, 2008.

TRIVIÑOS, Augusto N. S. Introdução à pesquisa em ciências sociais: a pesquisa qualitativa em educação. São Paulo: Atlas, 2009.

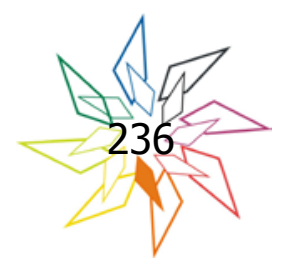

